\title{
SEJARAH PERDAGANGAN MARITIM RYUKYU SERTA HUBUNGANNYA DENGAN MELAKA
}

\author{
Azlansyah Aman \\ Azhar Mad Aros
}

\begin{abstract}
This article discusses the history of the Kingdom of Ryukyu, its role in maritime trade and relations with the Malay Sultanate of Malacca during the golden age of both kingdoms. The Kingdom of Ryukyu was an independent island nation located on the maritime crossroad between East Asia and Southeast Asia. On the other hand, the Malay Sultanate of Malacca was one of the most important trade centres in Southeast Asia in the 15th century and located on the Strait of Malacca, the world's busiest shipping lane. Historical records in foreign languages mention that the Kingdom of Ryukyu actively traded with the Malay Sultanate of Malacca and other Southeast Asian ports, and maintained tributary relations with China and Japan as well. The Ryukyuan traders connected the East Asia and Southeast Asia through maritime trade by transporting goods from and to both regions between 1373 and 1570 A.D, a span covering almost 200 years. In 1879 A.D, the Kingdom of Ryukyu was officially abolished, as it became an integral part of Japan during the Meiji Restoration.
\end{abstract}

\section{Pengenalan}

Kerajaan Ryukyu ialah sebuah kerajaan merdeka yang pernah wujud di kepulauan Ryukyu antara kurun ke-15 hingga kurun ke-19 Masihi sebelum Ryukyu diserap ke dalam negara Jepun pada tahun 1879 Masihi ketika zaman Pemulihan Meiji. Dinasti Sho di bawah kepimpinan Hashi (巴志) telah berjaya menyatukan kepulauan Okinawa, kepulauan Amami dan kepulauan Sakishima berdekatan Taiwan menjadi sebuah negara yang bersatu. Ketika berada di puncak kegemilangannya, Kerajaan Ryukyu pernah menjadi penghubung di antara Asia Timur dengan Asia Tenggara melalui perdagangan maritim. Dalam catatan berbahasa asing seperti Portugis dan China, Kerajaan Ryukyu turut dikenali dengan pelbagai nama. Antaranya ialah Leechew, Luchu, Loochoo, Liuchiu dan Gores. Pedagang Arab pula menyebut Ryukyu sebagai al-Ghur.

Dari segi geografi, kepulauan Ryukyu terletak di antara Laut China Timur di sebelah barat dan Laut Filipina di sebelah timur. Kepulauan ini mempunyai keluasan 3,090 kilometer persegi dan terdiri daripada 55 buah pulau yang dibahagikan kepada tiga kumpulan utama, iaitu kepulauan Amami di utara, kepulauan Okinawa di tengah dan kepulauan Sakishima di selatan. ${ }^{1}$ Pada hari ini, Ryukyu adalah sebahagian daripada negara Jepun dan dikenali sebagai Okinawa Prefecture ${ }^{2}$ yang mentadbir seluruh kepulauan Okinawa dan kepulauan Sakishima. Kepulauan Amami pula sudah tidak lagi berada di bawah pentadbiran Ryukyu kerana kepulauan tersebut telah diletakkan di bawah pentadbiran Kagoshima Prefecture. ${ }^{3}$

\section{Sejarah Kerajaan Ryukyu (1429-1879)}

Sebelum kepulauan Ryukyu disatukan menjadi sebuah kerajaan yang dikenali sebagai Kerajaan Ryukyu (琉球王国) oleh Hashi pada tahun 1429 Masihi, terdapat tiga buah kerajaan bebas di kepulauan Ryukyu, iaitu Hokuzan (北山), Chuzan (中山) dan Nanzan (南 山) pada kurun ke-14 Masihi. Ketiga-ketiga kerajaan tersebut mendapat nama berdasarkan lokasinya di pulau Okinawa. Kerajaan Hokuzan (Gunung Utara) terletak di utara, Chuzan 
(Gunung Tengah) terletak di tengah dan Nanzan (Gunung Selatan) pula terletak di selatan pulau Okinawa. Zaman ini dikenali sebagai Zaman Sanzan (三山) atau Zaman Tiga Gunung. Pada asalnya, Hashi hanyalah seorang anji (按司 $)^{4}$ atau pembesar tempatan sebelum beliau berjaya menyatukan ketiga-tiga kerajaan tersebut. Hashi mula menguasai pentadbiran Kerajaan Chuzan setelah beliau berjaya menggulingkan Raja Chuzan bernama Bunei pada tahun 1407 Masihi. Raja Bunei dihalau keluar dari istananya di Urosoe. Semenjak itu, tiada siapa yang tahu di mana Raja Bunei menghembuskan nafasnya yang terakhir. ${ }^{5}$ Meskipun Hashi menabalkan bapanya, Shisho sebagai Raja Chuzan, beliaulah yang memegang kuasa politik sebenar di sebalik tabir.

Kedua-dua raja tersebut mendapat pengiktirafan rasmi daripada Dinasti Ming di China dan dianugerahkan nama keluarga Sho (尚) dalam sebutan bahasa Ryukyu atau Shang dalam sebutan bahasa Cina. Ini merupakan permulaan kepada penubuhan Dinasti Sho yang berpusat di Istana Shuri (首里城) di tengah-tengah pulau Okinawa. Raja Sho Hashi (尚巴志) menaiki takhta setelah Raja Sho Shisho (尚思紹) mangkat pada tahun 1422 Masihi.

Kedudukan kepulauan Ryukyu yang strategik di persimpangan di antara Laut China Timur dan Laut China Selatan memberi kelebihan kepadanya dalam perdagangan maritim di Asia Timur dan Asia Tenggara. Seperti mana-mana kerajaan lain di Asia pada zaman itu, Kerajaan Ryukyu turut menghantar ufti kepada Kerajaan China. Sumber China, Ming Hui Tian Vol. 128 di bawah keterangan tentang Liu Ch'iu Kuo berbunyi:

The Major Ryukyu State paid the tributes irregularly, but sent her prince and envoy's son to study in the Imperial Institute and they had been well treated. The Minor Ryukyu State had never come nor paid tribute. There were three kings in the Ryukyu State. Early in the Reign of Hung Wu (1368-1398), Ch'ah Tu, King of Middle Mountain; Ch'eng Ch'ah Tu, King of Mountain's South; and P'oh Ni Chih, King of Mountain's North ${ }^{6}$, all sent their envoys paying tributes with horses and native products. In the $16^{\text {th }}$ Year of Reign of Hung Wu (1383), the emperor bestowed on them with gilded silver seals. In the $25^{\text {th }}$ year of the same reign (1392), King of Middle Mountain sent his son and nephew to study in the Imperial Institute. To encourage the King's regular homage and tribute, the Emperor bestowed on the King with 36 families of skillful navigators of Fukien. Since the Emperor Yung Leh ascended the throne (in 1403), successors of the three kings all of applied for His Majesty's investiture. Later, only the King of Middle Mountain paid homage. The surname of the King of Middle Mountain was 'Shang' (尚). He had been ordered to pay tribute two years once and the crew for each ship should not exceed 150 persons. The journey for homage started from Min District, Fukien Province, China. ${ }^{7}$

Hubungan China sebagai kerajaan penaung dengan kerajaan-kerajaan di Asia sebagai kerajaan uftian agak unik dan berbeza jika dibandingkan dengan amalan imperialis Barat pada zaman moden. Meskipun China menghendaki kerajaan-kerajaan di bawah naungannya menghantar ufti secara berkala kepada Maharaja China, namun setiap kerajaan yang terlibat itu masih dianggap sebagai kerajaan merdeka, bukan koloni atau jajahan kerajaan China. Malah, hanya kerajaan yang merdeka sahaja dibenarkan menghantar ufti kepada Maharaja China. Kerajaan China tidak pernah mengganggu pentadbiran kerajaankerajaan uftiannya. Kerajaan-kerajaan di bawah naungan China juga dibenarkan berdagang di beberapa pelabuhan tertentu di China. Kerajaan China juga bertindak sebagai kuasa besar yang menyelesaikan pertikaian di antara kerajaan-kerajaan naungannya. ${ }^{8}$

Kerajaan Ryukyu mencapai kegemilangannya dari penghujung kurun ke-14 hingga awal kurun ke-16 Masihi kerana penglibatannya dalam perdagangan maritim dalam skala yang besar. Pedagang-pedagang Ryukyu yang berulang alik dari Asia Timur ke Asia 
Tenggara menjadi penghubung di antara pelabuhan-pelabuhan entrepot di kedua-dua laut tersebut. Selain membuat hubungan perdagangan dengan China dan Jepun, pedagangpedagang Ryukyu turut mewujudkan hubungan perdagangan dengan Korea dan kerajaankerajaan di Asia Tenggara. ${ }^{9}$

Barang dagangan yang dibawa oleh pedagang Ryukyu dari Jepun ialah besi dan hasil kesenian. Dari Korea dan China pula, Ryukyu membawa herba, seramik dan tekstil. Barang dagangan tersebut akan dibawa ke pelabuhan-pelabuhan di Asia Tenggara seperti Siam, Melaka, Palembang, Jawa, Sumatera, Patani, Annam dan Sunda Kelapa untuk ditukar dengan gading, kayu beraroma, gula, rempah ratus, kulit haiwan dan pelbagai lagi hasil produk daripada haiwan.

Pada tahun 1609 Masihi, Ryukyu diceroboh dan dijajah oleh Satsuma-Han (薩摩 藩) ${ }^{10}$ dari Kagoshima, Jepun dengan restu Keshogunan Tokugawa di Edo (Tokyo pada masa kini) setelah kalah dalam beberapa siri peperangan. Meskipun Kerajaan Ryukyu berada di bawah jajahan Satsuma-Han, Kerajaan Ryukyu masih berterusan menghantar ufti kepada Dinasti Qing di China. Pada masa yang sama juga, Kerajaan Ryukyu turut menghantar ufti kepada Keshogunan Tokugawa serta masih meneruskan hubungan diplomatik dengan Korea. ${ }^{11}$

Bentuk penjajahan yang dialami oleh Ryukyu kelihatan agak longgar. Buktinya, meskipun tertakluk kepada kekuasaan Jepun menerusi Satsuma-Han dan pada masa yang sama juga masih kekal berada di bawah naungan China, Ryukyu masih mempunyai kebebasan untuk meneruskan perdagangan maritim walaupun tidak serancak dahulu. Ini adalah kerana Satsuma-Han memerlukan utusan dan pedagang Ryukyu menjadi mata-mata kepadanya bagi mengetahui hal ehwal di China. Malah, sebagai sebuah kerajaan uftian berautonomi kepada China dan Jepun, Ryukyu berjaya menjadikan dirinya sebagai sebuah pelabuhan entrepot yang utama di antara kedua-dua pasaran yang penting ini dengan Asia Tenggara. Pedagang-pedagang Ryukyu tidak menghadapi sebarang masalah membuka hubungan perdagangan dengan mana-mana pelabuhan yang mereka fikir boleh memberi keuntungan kepada mereka. ${ }^{12}$

Pada tanggal 11 Mac 1879, iaitu ketika Zaman Pemulihan Meiji, Kerajaan Ryukyu secara rasminya dibubarkan apabila Ryukyu diserap ke dalam negara Jepun sebagai Okinawa Prefecture. Raja terakhir Ryukyu bernama Raja Sho Tai (尚泰) bersama dengan keluarganya dipindahkan ke Tokyo dan diberi gelaran koushaku (侯爵) oleh Maharaja Jepun.

\section{Rekidai Hoan}

Meskipun pedagang-pedagang dari Ryukyu memainkan peranan yang amat penting dalam perdagangan maritim di antara Asia Timur dengan Asia Tenggara dengan menjadi jambatan penghubung di antara China dan Jepun dengan pelabuhan-pelabuhan di Asia Tenggara ketika era kegemilangannya, tidak banyak yang sarjana sejarah dapat ketahui tentang misi perdagangan dan diplomatik dari Ryukyu kerana tidak terdapat banyak rekod dalam bahasa asing seperti Portugis, Cina, Jepun dan Korea yang menyatakan tentangnya secara terperinci sehinggalah satu koleksi manuskrip ditemukan di Okinawa. ${ }^{13}$

Koleksi manuskrip itu dikenali sebagai Rekidai Hoan (歴代宝案) dalam bahasa Jepun atau Lidai Baoan dalam bahasa Cina atau Precious Documents of Successive Generations dalam bahasa Inggeris. Koleksi manuskrip Rekidai Hoan ini ditulis sepenuhnya dalam bahasa Cina dan mengandungi dokumen diplomatik di antara Kerajaan Ryukyu dengan China, Korea dan beberapa buah kerajaan di Asia Tenggara dari jangka masa tahun 1424 hingga tahun 1867 Masihi, iaitu kira-kira 444 tahun. Rekidai Hoan mengandungi 262 bab di dalam 18,260 buah folio ketika ditemui pada tahun 1932 Masihi. Selepas tahun 1933, dokumen ini dipindahkan ke Perpustakaan Okinawa Prefecture. Malangnya, perpustakaan tersebut 
musnah bersama-sama dengan dokumen ini ketika Pertempuran Okinawa semasa Perang Dunia Kedua. ${ }^{14}$

Mujurlah terdapat satu salinan Rekidai Hoan tersimpan di Taihoku Imperial University (kini National Taiwan University), Taipei. Salinan ini mengandungi 249 bab di dalam 17,271 buah folio. ${ }^{15}$ Meskipun salinan Rekidai Hoan ini tidak lengkap, namun dokumen ini merupakan sumber primer yang amat penting yang dapat digunakan oleh sarjana sejarah pada masa kini dalam mengkaji sejarah Ryukyu dan peranannya dalam perdagangan maritim dan jarak jauh di Asia Timur dan Asia Tenggara.

Dokumen-dokumen diplomatik yang terkandung di dalam salinan Rekidai Hoan ini adalah antara tahun 1424 hingga tahun 1867 Masihi, iaitu dari tahun ketiga pemerintahan Raja Sho Hashi hinggalah tahun kedua puluh pemerintahan Raja Sho Tai, iaitu Raja Ryukyu terakhir sebelum Kerajaan Ryukyu dibubarkan dan diserap ke dalam Jepun. ${ }^{16}$

Terjemahan dokumen Rekidai Hoan dari bahasa Cina ke bahasa Inggeris telah diusahakan oleh Atsushi Kobata dan Mitsugu Matsuda. Naskhah ini diterbitkan dengan judul Ryukyuan Relations with Korea and the South Sea Countries: An Annotated Translation of Documents in the Rekidai Hoan oleh Kawakita Printing pada tahun 1969 di Kyoto, Jepun. Anotasi ditambah pada naskhah ini bagi memudahkan kefahaman mengenai sejarah Ryukyu dan negara-negara yang terlibat. Usaha penterjemahan ini dilakukan antara tahun 1962 hingga 1963 di bawah naungan Institute of Advanced Projects, East-West Center, Honolulu, Hawaii. Kobayashi Atsushi bertanggungjawab mengusahakan penterjemahan Rekidai Hoan dari bahasa Cina ke bahasa Jepun dan menambah anotasi, manakala penterjemahan ke bahasa Inggeris dan penyemakan terjemahan bahasa Jepun dan anotasi pula dilakukan oleh Matsuda Mitsugu. ${ }^{17}$

Hubungan Ryukyu dengan Siam, Melaka, Jawa, Sumatera, Annam, Patani dan Palembang dari tahun 1425 hingga 1563 Masihi tercatat di dalam 108 dokumen di dalam bab 39 sehingga bab 43 di dalam Rekidai Hoan. Surat-surat yang dihantar daripada Kerajaan Ryukyu kepada kerajaan-kerajaan asing ditulis sepenuhnya dalam bahasa Cina oleh orang Cina dan keturunan mereka yang berhijrah dari Fukien di China ke Okinawa pada lewat kurun ke-14 Masihi. Penghijrahan mereka ke Okinawa adalah atas arahan Maharaja Ming untuk berkhidmat di istana Ryukyu sebagai malim atau jurumudi kapal, pembuat kapal, dan sarjana kesusasteraan dan kesenian. Penempatan mereka tertumpu di perkampungan pesisir pantai di Kumemura yang pada hari ini merupakan sebahagian bandar Naha. ${ }^{18}$

Surat-surat dari kerajaan-kerajaan di Asia Tenggara kepada Kerajaan Ryukyu juga ditulis dalam bahasa Cina. Kemungkinan besar kerajaan-kerajaan itu juga menggunakan khidmat penterjemah Cina yang terdiri daripada pedagang-pedagang dari China di pelabuhan masing-masing. Bahasa Cina dipercayai menjadi bahasa perhubungan di antara kerajaan-kerajaan Asia Tenggara dengan China dan Kerajaan Ryukyu.

Walaupun sesetengah surat daripada Kerajaan Ryukyu bertarikh sebelum tahun 1429 Masihi, iaitu sebelum Kerajaan Hokuzan, Chuzan dan Nanzan disatukan menjadi Kerajaan Ryukyu, kesemua surat tersebut ditulis oleh Raja Chuzan. ${ }^{19}$ Bilangan dokumen perhubungan di antara Kerajaan Ryukyu dengan kerajaan-kerajaan di Asia Tenggara yang terkandung di dalam Rekidai Hoan adalah seperti berikut:

1. Siam: 37 dokumen.

2. Melaka: 19 dokumen.

3. Palembang: 10 dokumen.

4. Jawa: 6 dokumen.

5. Sumatera: 3 dokumen.

6. Sunda-Kelapa: 2 dokumen.

7. Patani: 1 dokumen.

8. Annam: 1 dokumen. 


\section{Penglibatan Ryukyu Dalam Perdagangan Maritim}

Kerajaan Ryukyu terlibat dalam perdagangan maritim yang menghubungkan Asia Timur dengan Asia Tenggara antara tahun 1373 hingga tahun 1570 Masihi. ${ }^{20}$ Sepanjang jangka masa hampir dua abad itu, beberapa ratus kapal dari Ryukyu belayar merentasi Laut China Selatan menuju ke pelabuhan-pelabuhan di Asia Tenggara. Selain Melaka, pelabuhanpelabuhan lain yang turut dilawati oleh misi perdagangan dan diplomatik Ryukyu ialah Siam, Palembang, Jawa, Sumatera, Patani, Annam dan Sunda Kelapa. Misi perdagangan dan diplomatik dari Ryukyu ke Asia Tenggara bukan sahaja menaiki kapal Ryukyu, malah ada kalanya misi tersebut belayar ke Asia Tenggara dengan menumpang kapal dari China.

Jadual 1: Bilangan kapal dari Ryukyu ke Asia Tenggara

\begin{tabular}{|l|l|l|}
\hline Destinasi & $\begin{array}{l}\text { Jangka Waktu } \\
\text { (Tahun Masihi) }\end{array}$ & $\begin{array}{l}\text { Bilangan Kapal } \\
*(\text { ) Bilangan Kapal Yang Mengalami } \\
\text { Kecelakaan }{ }^{21}\end{array}$ \\
\hline Siam & $1419-1570$ & $62(4)$ \\
\hline Palembang & $1428-1440$ & 4 \\
\hline Jawa & $1430-1442$ & 6 \\
\hline Melaka & $1463-1511$ & $20(3)$ \\
\hline Sumatera & $1463-1468$ & 3 \\
\hline Patani & $1490-1543$ & 11 \\
\hline Annam & 1509 & 1 \\
\hline Sunda Kelapa & $1513-1518$ & 2 \\
\hline
\end{tabular}

Sumber: Arashiro Toshiaki, Ryukyu Okinawa Shi, Okinawa: Toyoukikaku, 2014, hlm. 82.

Salah satu faktor penting yang membawa kepada kemakmuran Ryukyu sebagai pusat perdagangan entrepot di Asia Timur ialah polisi Dinasti Ming di China yang mengharamkan urusan perdagangan maritim dilakukan secara persendirian di China. Polisi ini bermula seawal permulaan pemerintahan Dinasti Ming dan dikenali sebagai Ming Haijin (海禁) dalam bahasa Cina atau Ming Maritime Trade Ban dalam bahasa Inggeris. Polisi ini hanya membenarkan kerajaan-kerajaan uftian dengan China sahaja datang berdagang di China dan urusan perdagangan dikawal selia dengan ketat oleh China. Selain itu, populasi di persisiran pantai di China juga dipaksa berpindah ke daratan. ${ }^{22}$

Ming Haijin yang berlangsung dari tahun 1368 hingga tahun 1567 Masihi turut melarang rakyat China belayar ke luar negara. Orang asing pula hanya dibenarkan memasuki China menerusi rombongan misi ufti. Perdagangan ufti menghendaki kerajaan China memberikan hadiah dalam jumlah yang besar kepada kerajaan uftiannya. Ini menyebabkan banyak pihak tertarik menyertainya kerana rombongan mereka akan diberi makanan dan disediakan tempat tinggal sepanjang berada di China. Pada masa yang sama, mereka turut mengambil peluang menjalankan perdagangan persendirian secara senyap. ${ }^{23}$

Sebelum penyatuan Kerajaan Chuzan, Hokuzan dan Nanzan menjadi Kerajaan Ryukyu pada tahun 1429 Masihi, ketiga-tiga kerajaan tersebut diberikan status kerajaan uftian oleh Dinasti Ming dan dibenarkan berdagang dengan China secara rasmi. Selepas pembentukan Kerajaan Ryukyu oleh Hashi, hanya Kerajaan Ryukyu sahaja diberi status kerajaan uftian. Status kerajaan uftian ini telah menjadikan Ryukyu berperanan membawa barang dagangan dari wilayah-wilayah yang tidak mendapat kebenaran berdagang ke China seperti Jepun. Tujuan polisi ini diwujudkan oleh Dinasti Ming adalah bertujuan untuk mengawal aktiviti lanun dan menguatkuasakan cukai serta mengawal kuasa perdagangan..$^{24}$ 


\section{Hubungan Ryukyu Dengan Melaka}

Melaka berubah daripada sebuah perkampungan nelayan menjadi sebuah pelabuhan dan pusat perdagangan entrepot di Asia Tenggara pada awal abad ke-15 Masihi. Salah satu faktor utama yang membantu perkembangan Melaka ialah kedudukannya yang amat strategik kerana terletak di Selat Melaka, selat terpanjang di dunia yang menghubungkan di antara Arab dan India di sebelah barat dan China di sebelah timur. Selain pedagangpedagang dari Arab, India, China dan wilayah-wilayah sekitar Asia Tenggara, Melaka juga menjadi tumpuan pedagang-pedagang dari Ryukyu. Sebelum Portugis menakluki Melaka pada tahun 1511 Masihi, sekurang-kurangnya dua puluh buah kapal dari Ryukyu pernah datang berdagang di Melaka. ${ }^{25}$

Selain hasil laut, kepulauan Ryukyu tidak mempunyai hasil bumi yang banyak berbanding kerajaan-kerajaan di Asia Tenggara. Oleh yang demikian, Kerajaan Ryukyu terpaksa menghantar misi perdagangan ke pelabuhan-pelabuhan di Asia Tenggara bagi mendapatkan barang-barang untuk dijadikan ufti kepada Maharaja China di samping mendapatkan barang-barang untuk didagangkan dengan Jepun dan Korea.

Kapal-kapal dari Ryukyu belayar menuju Asia Tenggara dengan mengikuti arah tiupan angin monsun. Pelayaran dari Ryukyu berlepas pada bulan ke-8 atau ke- 9 dalam kalendar lunar kerana ketika itu monsun timur laut. Apabila mereka ingin pulang ke Ryukyu, mereka akan belayar pada bulan ke-3 atau ke-7 kerana ketika itu monsun barat daya pula. Mana-mana kapal yang terlepas angin monsun barat daya untuk pulang ke Ryukyu terpaksa menunggu lagi setahun. Pelayaran dari Ryukyu ke Asia Tenggara bermula dari pelabuhan Naha ke Kerama dan pulau-pulau Kume di kepulauan Ryukyu menuju pesisiran pantai Fukien di China. Kemudian, kapal-kapal itu akan belayar di sepanjang pesisiran pantai di tenggara China menuju ke Annam dan Siam dan dari situ belayar ke Palembang dan Jawa. Ada juga kapal-kapal dari Ryukyu yang belayar dari Siam ke Patani menuju ke Melaka dan dari situ belayar ke Sumatera dan Sunda. Biasanya, kapal-kapal dari Ryukyu akan sampai di Melaka dalam masa empat puluh enam hari sekiranya mendapat tiupan angin yang mencukupi. ${ }^{26}$

Bagi mengkaji berkenaan hubungan diplomatik di antara Kerajaan Ryukyu dengan Kerajaan Melaka pula, kita perlu merujuk Rekidai Hoan kerana naskhah ini merupakan satusatunya sumber primer yang boleh dipercayai dan masih wujud yang dapat digunakan oleh sejarawan masa kini dalam menganalisis hubungan ini. Terdapat 19 dokumen, iaitu 16 pucuk surat dan 3 sijil pelayaran di dalam Rekidai Hoan yang merupakan dokumen perhubungan di antara kedua-dua kerajaan.

Dokumen pertama di dalam Rekidai Hoan berkenaan hubungan Kerajaan Ryukyu dengan Kerajaan Melaka bertarikh T'ien-shun 7/8/427 (16 September 1463) dan dokumen terakhir pula bertarikh Cheng-te 6/8/13 (4 September 1511). Kemungkinan besar dokumen terakhir itu tidak sampai ke pengetahuan Kerajaan Melaka kerana tiada lagi perhubungan di antara kedua-dua kerajaan selepas kejatuhan Melaka di tangan Portugis pada 24 Ogos 1511.

Salinan Rekidai Hoan yang masih wujud itu bukanlah salinan yang lengkap. Masih ada lagi dokumen-dokumen yang hilang. Walau bagaimanapun, sekiranya dokumen yang bertarikh T'ien-shun 7/8/4 (16 September 1463) itu merupakan antara dokumen-dokumen perhubungan terawal daripada Raja Ryukyu kepada Sultan Melaka, maka kita dapat menduga bahawa perhubungan diplomatik dan perdagangan di antara Kerajaan Ryukyu dengan Kerajaan Melaka telah bermula selewat-lewatnya ketika pemerintahan Raja Sho Toku (尚德) di Ryukyu dan Sultan Mansur Shah di Melaka. Selain itu, dokumen ketiga daripada Raja Ryukyu kepada Sultan Melaka bertarikh Ch'eng-hua 1/8/15 (5 September 1465) pula dengan jelas menyebut nama Raja Sho Toku sebagai Raja Ryukyu yang mengutus 
surat tersebut kepada Sultan Melaka. Raja Sho Toku memerintah Ryukyu dari tahun 1461 hingga tahun 1469 Masihi. Bahagian permulaan dokumen tersebut berbunyi:

King Sho Toku of the Country of Ryukyu respectfully communicates with Your Majesty the King of the Country of Malacca. We sincerely believe that your virtues hold your people together and your benevolence extends to neighboring countries. You place confidence in other peoples and treat them well, and you welcome ships which come voyaging thousands of li. You take pleasure in being good to and loving people, thus attracting merchant-travelers from all directions. (Rekidai Hoan, Vol. XLI, Doc. No.8) ${ }^{28}$

Satu lagi bukti yang mengukuhkan penyataan bahawa hubungan diplomatik dan perdagangan di antara Kerajaan Ryukyu dengan Kerajaan Melaka dipercayai telah bermula ketika pemerintahan Raja Sho Toku dan Sultan Mansur Shah ialah kandungan dokumen yang dihantar oleh Raja Ryukyu kepada Sultan Melaka pada tahun 1470 Masihi. Sebahagian kandungan dokumen tersebut berbunyi:

The King of the country of Ryukyu addresses Your Majesty the King of the country of Malacca in this dispatch. We have learned with respect that the excellent qualities of you, the Virtuous King are gifts of Heaven, and that inheriting the territory to rule, you bestowed your benevolence upon the people, and glorious reputation spread far and near. Since our royal predecessor laid the foundations in the beginning, we have maintained the association and have continued to received your inquiries. We have succeeded to the administration of this petty country, and while we attend to our duties with humility and reverence, we have been honored to be granted you king favors and presents. We shall always keep this in mind and never forget it. (Rekidai Hoan, Vol. XLI, Doc. No. 16) ${ }^{29}$

Surat tersebut dipercayai ditulis oleh Raja Sho En (尚圓) kerana baginda memerintah kerajaan Ryukyu dari tahun 1470 hingga tahun 1476 Masihi. Memandangkan di dalam surat tersebut ada menyatakan bahawa hubungan di antara kerajaan Ryukyu dengan Kerajaan Melaka telah dimulakan oleh seorang Raja Ryukyu yang memerintah sebelum Raja Sho En, maka dapatlah dibuat kesimpulan bahawa Raja Sho Toku ialah Raja Ryukyu pertama yang menjalinkan hubungan diplomatik dan perdagangan dengan Sultan Melaka.

Jadual 2: Nama Raja Ryukyu dan Sultan Melaka ketika perhubungan di antara Kerajaan Ryukyu dengan Kerajaan Melaka berlangsung dari tahun 1463 hingga tahun 1511 Masihi

\begin{tabular}{|l|l|l|l|}
\hline $\begin{array}{l}\text { Nama } \\
\text { Raja Ryukyu }\end{array}$ & $\begin{array}{l}\text { Tahun } \\
\text { Pemerintahan }\end{array}$ & $\begin{array}{l}\text { Nama } \\
\text { Sultan Melaka }\end{array}$ & $\begin{array}{l}\text { Tahun } \\
\text { Pemerintahan }\end{array}$ \\
\hline Raja Sho Toku & $1461-1469$ & Sultan Mansur Shah & $1456-1477$ \\
\hline Raja Sho En & $1470-1476$ & Sultan Alauddin Riayat Shah & $1477-1488$ \\
\hline Raja Sho Sen-I & 1477 & Sultan Mahmud Shah & $1488-1511$ \\
\hline Raja Sho Shin & $1477-1526$ & \multicolumn{2}{|l}{} \\
\cline { 1 - 2 } & Ang &
\end{tabular}

Sumber: Richard Pearson, Ancient Ryukyu: An Archaeological Study of Island Communities, Honolulu: University of Hawai'i Press, 2013, hlm. 323 dan Syed Ahmad Syed Kassim (dll), Melaka: Di Sinilah Segala-galanya Bermula, Penerbit Universiti Tun Huessein Onn Malaysia (UTHM), 2012, hlm. 36.

Meskipun terdapat enam pucuk surat daripada Kerajaan Melaka kepada Kerajaan Ryukyu di dalam Rekidai Hoan, tetapi bukan kesemuanya ditulis oleh Sultan Melaka. Tiga pucuk surat ditulis oleh Sultan Melaka dan tiga pucuk surat lagi ditulis oleh seseorang yang 
bergelar Laksamana Melaka. Surat yang ditulis oleh Laksamana Melaka itu ditulis pada tahun 1480 dan tahun 1481 Masihi, iaitu ketika pemerintahan Sultan Alauddin Riayat Shah.

Sultan Alauddin Riayat Shah ialah putera Sultan Mansur Shah dengan anak perempuan Hang Tuah. Sultan Alauddin Riayat Shah menaiki takhta pada usia enam tahun selepas kemangkatan Sultan Mansur Shah..$^{30}$ Laksamana Melaka yang menulis surat kepada Raja Ryukyu itu diyakini ialah Hang Tuah kerana beliau berkhidmat sebagai Laksamana Melaka ketika pemerintahan Sultan Muzaffar Shah, Sultan Mansur Shah dan Sultan Alauddin Riayat Shah. ${ }^{31}$

Seperti yang telah dipaparkan pada Jadual 1, dua puluh buah kapal dari Ryukyu telah belayar ke Melaka. Malangnya, tiga buah kapal telah mengalami kecelakaan (terdampar atau karam). Di dalam surat bertarikh Ch'eng-hua 16/3/2 (11 April 1480) daripada Laksamana Melaka kepada Raja Ryukyu, Laksamana Melaka memaklumkan bahawa beliau telah menghantar utusan dari Melaka ke Chan-ch'eng (Champa: Annam) apabila mendapat khabar tentang sebuah kapal Ryukyu terdampar di Chiao-Chih (utara Annam). Anak-anak kapal Ryukyu itu telah diserang oleh orang Chiao-Chih ketika mereka hendak mendapatkan air. Utusan dari Melaka berjaya menemui dua orang utusan Ryukyu itu, tetapi seorang daripadanya mati kerana sakit tidak lama selepas itu.

Ringkasan isi kandungan surat-surat perhubungan di antara Kerajaan Ryukyu dengan Kerajaan Melaka boleh dilihat pada jadual di bawah ini.

\section{Jadual 3: Surat di Dalam Rekidai Hoan Tentang Perhubungan di Antara Kerajaan Ryukyu Dengan Kerajaan Melaka}

\begin{tabular}{|c|c|c|}
\hline Bil. & No. Dokumen & Ringkasan Isi Kandungan Surat \\
\hline 1 & $\begin{array}{l}\text { Vol. XLI, } \\
\text { Doc. No. } 1\end{array}$ & $\begin{array}{l}\text { Surat daripada Raja Ryukyu kepada Sultan Melaka bertarikh T'ien- } \\
\text { shun } 7 / 8 / 4 \text { (16 September 1463). Raja Ryukyu berterima kasih kepada } \\
\text { Sultan Melaka kerana memberinya hadiah ketika rombongan } \\
\text { terdahulu. Raja Ryukyu mengutus ketua utusan bernama Gushiken } \\
\text { untuk menyampaikan hadiah kepada Sultan Melaka. Rombongan } \\
\text { Ryukyu membawa barang-barang untuk didagangkan di Melaka. Raja } \\
\text { Ryukyu memohon Sultan Melaka membenarkan rombongan Ryukyu } \\
\text { menjalankan urusan perdagangan secepat mungkin agar mereka } \\
\text { dapat pulang dengan mengikuti tiupan angin monsun yang akan } \\
\text { datang. } \\
\text { Hadiah (bilangan): Satin berwarna ( } 5 \text { gulung), pedang (5), pasu biru } \\
\text { besar (20), mangkuk biru (2,000), satin biru ( } 20 \text { bolts), kipas (30), pasu } \\
\text { biru kecil ( }(40) \\
\text { Nama kapal: Kushira-maru } \\
\text { Utusan: Ketua utusan Gushiken, timbalan ketua utusan Nakamini dan } \\
\text { jurubahasa Den Tai dan Tei Ketsu }\end{array}$ \\
\hline 2 & $\begin{array}{l}\text { Vol. XLI, } \\
\text { Doc. No. } 5\end{array}$ & $\begin{array}{l}\text { Surat daripada Raja Ryukyu kepada Sultan Melaka bertarikh T'ien- } \\
\text { shun } 8 / 8 / 9 \text { (10 September 1464). Raja Ryukyu berterima kasih kepada } \\
\text { Sultan Melaka kerana rombongan Ryukyu terdahulu dibenarkan } \\
\text { berdagang di Melaka tanpa gangguan. Raja Ryukyu mengutus ketua } \\
\text { utusan Takushi dan jurubahasa Sai Kaiho untuk bertukar-tukar hadiah } \\
\text { dengan Sultan Melaka. Raja Ryukyu memohon Sultan Melaka } \\
\text { membenarkan rombongan Ryukyu menjalankan urusan perdagangan } \\
\text { secepat mungkin agar mereka dapat pulang dengan segera. } \\
\text { Hadiah (bilangan): Satin pelbagai warna ( } 5 \text { gulung), pedang (5), pasu } \\
\text { biru besar (20), mangkuk biru (2,000), satin biru (20 gulung), kipas } \\
\text { (30), pasu biru kecil (400) } \\
\text { Nama kapal: Tukumasari } \\
\text { Utusan: Ketua utusan Takushi dan jurubahasa Sai Kaiho }\end{array}$ \\
\hline
\end{tabular}




\begin{tabular}{|c|c|c|}
\hline 3 & $\begin{array}{l}\text { Vol. XLI, } \\
\text { Doc. No. } 8\end{array}$ & $\begin{array}{l}\text { Surat daripada Raja Ryukyu bernama Raja Sho Toku kepada Sultan } \\
\text { Melaka bertarikh Ch'eng-hua 1/8/15 (5 September 1465). Raja Ryukyu } \\
\text { berterima kasih kerana mendapat banyak hadiah daripada Sultan } \\
\text { Melaka ketika rombongan terdahulu. Raja Ryukyu mengutus ketua } \\
\text { utusan Ufuzatu, jurubahasa Sai Kaiho dan lain-lain untuk bertukar- } \\
\text { tukar hadiah dengan Sultan Melaka. Raja Ryukyu memohon Sultan } \\
\text { Melaka membenarkan rombongan Ryukyu berdagang di jalan-jalan } \\
\text { dan pasar-pasar di Melaka dan membenarkan rombongan Ryukyu } \\
\text { pulang dengan segera. } \\
\text { Hadiah (bilangan): Satin berwarna ( } 5 \text { gulung), pedang (5), pasu besar } \\
\text { biru (20), mangkuk biru (2,000), satin biru ( } 20 \text { gulung), kipas (30), pasu } \\
\text { biru kecil (400) } \\
\text { Nama kapal: Tuguchi-maru } \\
\text { Utusan: ketua utusan Ufuzatu, dua orang timbalan ketua utusan, } \\
\text { jurubahasa Sai Kaiho }\end{array}$ \\
\hline 4 & $\begin{array}{l}\text { Vol. XLI, } \\
\text { Doc. No. } 9\end{array}$ & $\begin{array}{l}\text { Surat daripada Raja Ryukyu kepada Sultan Melaka bertarikh Ch'eng- } \\
\text { hua 2/10/2 ( } 9 \text { November 1466). Raja Ryukyu berterima kasih kerana } \\
\text { mendapat banyak hadiah daripada Sultan Melaka ketika rombongan } \\
\text { terdahulu. Raja Ryukyu mengutus ketua utusan Takushi, jurubahasa } \\
\text { Sai Kaiho dan lain-lain untuk bertukar-tukar hadiah dengan Sultan } \\
\text { Melaka. Raja Ryukyu memohon Sultan Melaka membenarkan } \\
\text { rombongannya berdagang di Melaka dan pulang dengan segera. } \\
\text { Hadiah (bilangan): Satin pelbagai warna ( } 5 \text { gulung), pedang (5), pasu } \\
\text { biru besar (20), mangkuk biru (2,000), satin biru ( } 20 \text { gulung), kipas } \\
\text { (40), pasu biru kecil (400) } \\
\text { Utusan: Ketua utusan Takushi, timbalan ketua utusan Gibu dan } \\
\text { Amuru, jurubahasa Sai Kaiho }\end{array}$ \\
\hline 5 & $\begin{array}{l}\text { Vol. XXXIX, } \\
\text { Doc. No. } 4\end{array}$ & $\begin{array}{l}\text { Surat daripada Sultan Melaka kepada Raja Ryukyu bertarikh Ch'eng- } \\
\text { hua } 3 / 3 / 20 \text { (23 April 1467). Sultan Melaka berterima kasih kepada Raja } \\
\text { Ryukyu kerana mengutus rombongan dari Ryukyu ke Melaka. Sultan } \\
\text { Melaka menzahirkan keinginan menghantar utusan dari Melaka ke } \\
\text { Ryukyu, tetapi belum berkesempatan. Sultan Melaka menzahirkan } \\
\text { kegembiraan sekiranya Raja Ryukyu sudi menerima hadiah daripada } \\
\text { Kerajaan Melaka. } \\
\text { Hadiah (bilangan): Hao San-lien ta-pu ( } 20 \text { gulung), hsi-chiao-ta-qu (9 } \\
\text { gulung), chiao-ta-pu (10 gulung), nan-mo-na-pu (11 gulung) }{ }^{32}\end{array}$ \\
\hline 6 & $\begin{array}{l}\text { Vol XLI, } \\
\text { Doc. No. } 11\end{array}$ & $\begin{array}{l}\text { Surat daripada Raja Ryukyu kepada Sultan Melaka bertarikh Ch'eng- } \\
\text { hua 3/8/? (- 1467). Raja Ryukyu berterima kasih kerana mendapat } \\
\text { banyak hadiah daripada Sultan Melaka ketika rombongan terdahulu. } \\
\text { Raja Ryukyu mengutus ketua utusan Shimabuku, jurubahasa Sai } \\
\text { Kaiho dan lain-lain untuk bertukar-tukar hadiah dengan Sultan } \\
\text { Melaka. Raja Ryukyu memohon Sultan Melaka membenarkan } \\
\text { rombongannya berdagang di Melaka dan pulang dengan segera. } \\
\text { Hadiah (bilangan): Satin berwarna ( } 5 \text { gulung), pedang (5), pasu biru } \\
\text { besar (20), mangkuk biru (2,000), satin biru (20 gulung), kipas (30), } \\
\text { pasu biru kecil (400) } \\
\text { Utusan: Ketua utusan Shimabuku, timbalan ketua utusan Jana Utchi } \\
\text { dan Ufuzatu, jurubahasa Sai Kaiho dan Rin Sho }\end{array}$ \\
\hline 7 & $\begin{array}{l}\text { Vol. XLI, } \\
\text { Doc. No. } 12\end{array}$ & $\begin{array}{l}\text { Surat daripada Raja Ryukyu kepada Sultan Melaka bertarikh Ch'eng- } \\
\text { hua 4/8/15 (1 September 1468). Raja Ryukyu berterima kasih kerana } \\
\text { mendapat banyak hadiah daripada Sultan Melaka ketika rombongan } \\
\text { terdahulu. Raja Ryukyu mengutus ketua utusan Amuru, jurubahasa } \\
\text { Sai Kaiho dan lain-lain untuk bertukar-tukar hadiah dengan Sultan } \\
\text { Melaka. Raja Ryukyu memohon Sultan Melaka membenarkan } \\
\text { rombongannya berdagang di Melaka dan pulang dengan segera. }\end{array}$ \\
\hline
\end{tabular}




\begin{tabular}{|c|c|c|}
\hline & & $\begin{array}{l}\text { Hadiah (bilangan): Satin berwarna ( } 5 \text { gulung), pedang (5), pasu biru } \\
\text { besar (20), mangkuk biru (2,000), satin biru ( } 20 \text { gulung), kipas (30), } \\
\text { pasu biru kecil ( } 400) \\
\text { Utusan: Ketua utusan Amuru, timbalan ketua utusan Nako dan } \\
\text { Shimajiri, jurubahasa Sai Kaiho dan Rin Sho }\end{array}$ \\
\hline 8 & $\begin{array}{l}\text { Vol. XXXIX, } \\
\text { Doc. No. } 7\end{array}$ & $\begin{array}{l}\text { Surat daripada Sultan Melaka kepada Raja Ryukyu bertarikh Ch'eng- } \\
\text { hua 5/1/26 (7 Februari 1469). Sultan Melaka menzahirkan } \\
\text { kegembiraan menerima kedatangan utusan Amuru, jurubahasa Kaiho } \\
\text { dan lain-lain ke Melaka. Sultan Melaka memuji-muji kelakuan } \\
\text { rombongan Ryukyu di Melaka. Sultan Melaka menawarkan hadiah } \\
\text { kepada Raja Ryukyu. Sultan Melaka berharap agar rombongan dari } \\
\text { Ryukyu dapat datang ke Melaka setiap tahun. } \\
\text { Hadiah (bilangan): Pieh-pu hao-pe (11 gulung), pieh-ti-pu (19 gulung), } \\
\text { nan-mu-na (10 gulung), shan-nan-pa hao-pe (5 gulung), tso-ta (5 } \\
\text { gulung) }{ }^{33}\end{array}$ \\
\hline 9 & $\begin{array}{l}\text { Vol. XLI, } \\
\text { Doc. No. } 14\end{array}$ & $\begin{array}{l}\text { Surat daripada Raja Ryukyu kepada Sultan Melaka bertarikh Ch'eng- } \\
\text { hua 5/8/15 (20 September 1469). Raja Ryukyu mengutus ketua utusan } \\
\text { Ufusiku dan jurubahasa Rin Sho untuk bertukar-tukar hadiah dengan } \\
\text { Sultan Melaka. Raja Ryukyu memohon Sultan Melaka membenarkan } \\
\text { rombongannya berdagang di Melaka dan pulang dengan segera. } \\
\text { Hadiah (bilangan): Satin berwarna ( } 5 \text { gulung), pedang (5), pasu biru } \\
\text { besar (20), mangkuk biru (2,000), satin biru (20 gulung), kipas (30), } \\
\text { pasu biru kecil (400) } \\
\text { Utusan: Ketua utusan Ufusiku, jurubahasa Rin Sho dan Chin Tai }\end{array}$ \\
\hline 10 & $\begin{array}{l}\text { Vol. XXXIX, } \\
\text { Doc. No. } 8\end{array}$ & $\begin{array}{l}\text { Surat daripada Sultan Melaka kepada Raja Ryukyu bertarikh Ch'eng- } \\
\text { hua 6/3/? (-1470). Sultan Melaka menyatakan hasrat menghantar } \\
\text { utusan dari Melaka ke Ryukyu tetapi baginda membatalkan hasrat itu } \\
\text { kerana tidak biasa dengan laluan laut ke Ryukyu. Sultan Melaka } \\
\text { menawarkan hadiah kepada Raja Ryukyu. Sultan Melaka memuji-muji } \\
\text { kelakuan rombongan Ryukyu di Melaka, tetapi baginda menyatakan } \\
\text { bahawa ada seorang ahli rombongan yang berkelakuan tidak baik. } \\
\text { Sultan Melaka memohon agar dihantar orang yang berkelakuan baik } \\
\text { pada masa hadapan. } \\
\text { Hadiah (bilangan): Je-na-li ( } 1 \text { gulung), pi-pu (5 gulung), hsi shao-ta-pu (4 } \\
\text { gulung), shao-ta-pu ( } 40 \text { gulung) }\end{array}$ \\
\hline 11 & $\begin{array}{l}\text { Vol. XLI, } \\
\text { Doc. No. } 16\end{array}$ & $\begin{array}{l}\text { Surat daripada Raja Ryukyu kepada Sultan Melaka bertarikh Ch'eng- } \\
\text { hua 6/?/? (-1470). Raja Ryukyu mengutus ketua utusan Amuru dan } \\
\text { jurubahasa Chin Tai untuk bertukar-tukar hadiah dengan Sultan } \\
\text { Melaka. Raja Ryukyu terkejut apabila mengetahui ada ahli rombongan } \\
\text { Ryukyu yang berkelakuan tidak baik di Melaka. Raja Ryukyu } \\
\text { meminta agar Sultan Melaka melaporkan kepadanya dengan segera } \\
\text { sekiranya perkara ini berlaku lagi supaya baginda dapat menghukum } \\
\text { mereka. Raja Ryukyu memohon Sultan Melaka membenarkan } \\
\text { rombongannya berdagang di Melaka dan pulang dengan segera. } \\
\text { Hadiah (bilangan): Satin berwarna ( } 5 \text { gulung), pedang (5), pasu biru } \\
\text { besar (20), mangkuk biru (2,000), satin biru (20 gulung), kipas (30), } \\
\text { pasu biru kecil (400) }\end{array}$ \\
\hline 12 & $\begin{array}{l}\text { Vol. XLI, } \\
\text { Doc. No. } 18\end{array}$ & $\begin{array}{l}\text { Surat daripada Raja Ryukyu kepada Sultan Melaka bertarikh Ch'eng- } \\
\text { hua } 8 / 9 / 20 \text { (21 Oktober 1472). Raja Ryukyu mengutus ketua utusan } \\
\text { Ufutaru dan jurubahasa (nama tidak dapat dikenal pasti) dan lain-lain } \\
\text { untuk bertukar-tukar hadiah dengan Sultan Melaka. Raja Ryukyu } \\
\text { memaklumkan bahawa dua buah kapal telah belayar dari Ryukyu ke } \\
\text { Melaka pada tahun lepas membawa jurubahasa Rin Sho, Chin Tai dan } \\
\text { lain-lain masih belum pulang ke Ryukyu. Baginda khuatir kedua-dua } \\
\text { kapal tersebut telah ditimpa kecelakaan dan meminta bantuan Sultan }\end{array}$ \\
\hline
\end{tabular}




\begin{tabular}{|c|c|c|}
\hline & & $\begin{array}{l}\text { Melaka mencarinya. Raja Ryukyu memohon Sultan Melaka } \\
\text { membenarkan rombongannya berdagang di Melaka dan pulang } \\
\text { dengan segera. Hadiah dan bilangannya tidak dinyatakan di dalam } \\
\text { surat ini. }\end{array}$ \\
\hline 13 & $\begin{array}{l}\text { Vol. XLI, } \\
\text { Doc. No. } 19\end{array}$ & $\begin{array}{l}\text { Surat daripada Raja Ryukyu kepada Sultan Melaka bertarikh Ch'eng- } \\
\text { hua } 8 / 9 / 28 \text { (29 Oktober 1472). Raja Ryukyu berterima kasih kepada } \\
\text { Sultan Melaka kerana mendapat hadiah. Raja Ryukyu mengutus ketua } \\
\text { utusan Shimajiri, jurubahasa Chin Yo dan lain-lain untuk bertukar- } \\
\text { tukar hadiah dengan Sultan Melaka. Raja Ryukyu memohon Sultan } \\
\text { Melaka membenarkan rombongannya berdagang di Melaka dan } \\
\text { pulang dengan segera. Hadiah dan bilangannya tidak dinyatakan di } \\
\text { dalam surat ini. }\end{array}$ \\
\hline 14 & $\begin{array}{l}\text { Vol. XXXIX, } \\
\text { Doc. No. } 9\end{array}$ & $\begin{array}{l}\text { Surat daripada Sultan Melaka kepada Raja Ryukyu ini ditulis oleh } \\
\text { wakil sultan bertarikh Ch'eng-hua 16/2/? (-1480). Sultan Melaka } \\
\text { memaklumkan kepada Raja Ryukyu bahawa baginda baru berusia } 6 \\
\text { tahun dan merujuk Raja Ryukyu sebagai "Your Fatherly Majesty of } \\
\text { Ryukyu." Sultan Melaka menyebut nama utusan Shimajiri dan } \\
\text { jurubahasa Tei Raku bersama-sama dengan rombongan Ryukyu telah } \\
\text { datang ke Melaka. Sultan Melaka menyatakan keinginan untuk } \\
\text { menghantar utusan dari Melaka ke Ryukyu, tetapi tidak } \\
\text { berkesempatan. Sultan Melaka menzahirkan kegembiraan sekiranya } \\
\text { Raja Ryukyu sudi menerima hadiah daripada Kerajaan Melaka. } \\
\text { Hadiah (bilangan): Shan-nan-pu (10 gulung), nan-mu-na (10 gulung), } \\
\text { huo-wai (10 gulung), sheng-chia-sha (10 gulung), shan-nan-pu wen-ti-li (10 } \\
\text { gulung) }{ }^{35}\end{array}$ \\
\hline 15 & $\begin{array}{l}\text { Vol. XXXIX, } \\
\text { Doc. No. } 10\end{array}$ & $\begin{array}{l}\text { Surat daripada Laksamana Melaka kepada Raja Ryukyu bertarikh } \\
\text { Ch'eng-hua } 16 / 3 / 2 \text { (11 April 1480). Laksamana Melaka memaklumkan } \\
\text { bahawa salah sebuah kapal Ryukyu yang hilang itu telah dijumpai } \\
\text { terdampar di Chiao-chih (utara Annam). Mereka telah diserang oleh } \\
\text { penduduk Chiao-chih ketika sedang mendapatkan air. Selepas } \\
\text { mengetahui tentang hal ini, Laksamana Melaka telah menghantar } \\
\text { utusan dari Melaka dengan sebuah kapal kecil ke Chan-ch'eng } \\
\text { (Champa; Annam). Selepas melakukan siasatan, utusan Melaka } \\
\text { berjaya menemukan dua orang utusan Ryukyu, tetapi seorang } \\
\text { daripadanya mati tidak lama selepas itu kerana sakit. Laksamana } \\
\text { Melaka memaklumkan bahawa rombongan dari Ryukyu dan } \\
\text { jurubahasa Tei Raku telah datang ke Melaka dan pulang ke Ryukyu } \\
\text { setelah selesai urusan perdagangan mereka. Laksamana Melaka } \\
\text { menyatakan bahawa beliau berkhidmat untuk Kerajaan Melaka dan } \\
\text { turut berkhidmat untuk Raja Ryukyu atas urusan ini. Laksamana } \\
\text { Melaka memohon Raja Ryukyu agar menganugerahkan sebilah } \\
\text { pedang, sebuah alat melaras busar dan sebuah pelana kuda } \\
\text { kepadanya. }\end{array}$ \\
\hline 16 & $\begin{array}{l}\text { Vol. XXXIX, } \\
\text { Doc. No. } 15\end{array}$ & $\begin{array}{l}\text { Surat daripada Sultan Melaka kepada Raja Ryukyu ini ditulis oleh } \\
\text { Laksamana Melaka bertarikh Ch'eng-hua 17/3/?/(-1481). Sultan } \\
\text { Melaka merujuk Raja Ryukyu sebagai "Our brother king." Sultan } \\
\text { Melaka memaklumkan bahawa rombongan Ryukyu telah datang ke } \\
\text { Melaka dan dibenarkan berdagang tanpa sekatan. Sultan Melaka } \\
\text { menghadiahkan arak berwarna kepada rombongan Ryukyu dan } \\
\text { membenarkan mereka pulang ke Ryukyu. } \\
\text { Hadiah (bilangan): Chi-ti-pu (20 gulung), hsing-chi-chih (14 gulung), lin- } \\
\text { wu-na (12 gulung), shan-nan-pi (4 gulung) }\end{array}$ \\
\hline
\end{tabular}

Sumber: Kobata Atsushi dan Matsuda Mitsugu, Ryukyuan Relations with Korea and the South Sea Countries: An Annotated Translation of Documents in the Rekidai Hoan, Kyoto: Kawakita Printing, 1969, hlm. 104-121. 
Selain surat-surat perhubungan di antara Kerajaan Ryukyu dengan Kerajaan Melaka, terdapat 3 sijil pelayaran terkandung di dalam Rekidai Hoan berkenaan dengan misi diplomatik dan perdagangan Ryukyu ke Melaka. Sijil pelayaran ialah suatu sijil yang mengesahkan pembawa sijil berkenaan ialah utusan rasmi Kerajaan Ryukyu. Tanpa sijil pelayaran, rombongan dari Ryukyu berisiko ditahan oleh pihak berkuasa China kerana disalah anggap sebagai lanun $w a k o^{37}$ dari Jepun.

Ringkasan isi kandungan sijil-sijil pelayaran di antara Kerajaan Ryukyu dengan Kerajaan Melaka boleh dilihat pada jadual di bawah ini.

\section{Jadual 4: Sijil-sijil Pelayaran Ryukyu ke Melaka}

\begin{tabular}{|c|c|c|}
\hline Bil. & No. Dokumen & Ringkasan Isi Kandungan Sijil Pelayaran \\
\hline 1 & $\begin{array}{l}\text { Vol. XLII, } \\
\text { Doc. No. } 3\end{array}$ & $\begin{array}{l}\text { Sijil pelayaran Ryukyu ke Melaka bercop perkataan Hsuan dan } \\
\text { nombor } 174 \text { bertarikh Cheng-te } 4 / 8 / 18 \text { ( } 2 \text { September 1509). } \\
\text { Ketua utusan: Kamadu } \\
\text { Timbalan ketua utusan: Manyuku, Gurami } \\
\text { Jurubahasa: Ko Ken, Ko Ga } \\
\text { Jurumudi: Ryo Jitsu } \\
\text { Pengurus am kapal: Mabuta } \\
\text { Bilangan ahli rombongan termasuk anak kapal: } 150 \text { orang }\end{array}$ \\
\hline 2 & $\begin{array}{l}\text { Vol. XLII, } \\
\text { Doc. No. } 6\end{array}$ & $\begin{array}{l}\text { Sijil pelayaran Ryukyu ke Melaka bercop perkataan Hsuan dan } \\
\text { nombor } 181 \text { bertarikh Cheng-te 5/8/19 (21 September 1510). } \\
\text { Ketua utusan: Ufumafutu } \\
\text { Timbalan ketua utusan: Makani, Taru } \\
\text { Jurubahasa: Ko Ken, Ko Shin } \\
\text { Jurumudi: Sai Teki } \\
\text { Pengurus am kapal: Masanru } \\
\text { Bilangan ahli rombongan termasuk anak kapal: } 200 \text { orang }\end{array}$ \\
\hline 3 & $\begin{array}{l}\text { Vol. XLII, } \\
\text { Doc. No. } 7\end{array}$ & $\begin{array}{l}\text { Sijil pelayaran Ryukyu ke Melaka bercop perkataan Hsuan dan } \\
\text { nombor } 188 \text { bertarikh Cheng-te 6/18/13 (4 September 1511). } \\
\text { Ketua utusan: Mafibi } \\
\text { Timbalan ketua utusan: Mamitsu, Yamatu } \\
\text { Jurubahasa: Ryo Ketsu, Ko Ga } \\
\text { Jurumudi: Ryo Jitsu } \\
\text { Pengurus am kapal: Futu } \\
\text { Bilangan ahli rombongan termasuk anak kapal: } 203 \text { orang }\end{array}$ \\
\hline
\end{tabular}

Sumber: Kobata Atsushi dan Matsuda Mitsugu, Ryukyuan Relations with Korea and the South Sea Countries: An Annotated Translation of Documents in the Rekidai Hoan, Kyoto: Kawakita Printing, 1969, hlm. 123-125.

Antara tahun 1482 hingga tahun 1508 Masihi, tidak dijumpai sebarang dokumen perhubungan di antara Kerajaan Ryukyu dengan Kerajaan Melaka di dalam Rekidai Hoan. Kemungkinan besar perhubungan di antara kedua-kedua kerajaan masih berlangsung dalam tempoh tersebut, tetapi dokumen berkaitan telah hilang atau musnah.

Selain Rekidai Hoan, terdapat beberapa sumber Portugis yang mencatatkan tentang kegiatan pedagang Ryukyu di Melaka. Salah satunya ialah catatan Tome Pires di dalam bukunya, Suma Oriental. Menurut Tome Pires, pedagang Ryukyu membawa emas, tembaga, pelbagai jenis senjata, peti simpanan, kotak bersalut emas, kipas dan gandum ke Melaka untuk didagangkan. Emas yang dibawa mereka amat banyak. Selain itu, pedagang Ryukyu juga membawa banyak lada hitam, sutera pelbagai warna, kasturi, tembikar, kain tenunan, bawang dan sayur-sayuran. Mereka amat meminati kain dari Bengal dan arak Melaka. ${ }^{38}$ Pedagang Ryukyu menjual pedang dengan harga tiga puluh cruzados sebilah. ${ }^{39}$ 
Pedagang Ryukyu datang ke Melaka dengan dua atau tiga buah jong setiap tahun. Ada kalanya mereka menumpang jong dari China. Pedagang Ryukyu membawa barangbarang dari Melaka ke Jepun untuk ditukarkan dengan emas dan tembaga. Emas dan tembaga yang dibawa oleh pedagang Ryukyu ke Melaka berasal dari Jepun. Jepun tidak mempunyai hubungan perdagangan dengan Melaka kerana Jepun tidak mempunyai jong dan orang Jepun bukanlah pelayar. ${ }^{40}$

Tome Pires turut mencatatkan di dalam Suma Oriental tentang sikap dan keperibadian pedagang Ryukyu. Menurutnya, pedagang Ryukyu ialah pedagang yang boleh dipercayai. Mereka tidak membeli dan menjual hamba abdi. Pedagang Ryukyu berkulit cerah dan berpakaian lebih kemas, lebih baik daripada pedagang Cina dan mereka lebih dihormati. Pedagang Ryukyu juga menyembah berhala. Sekiranya mereka berjaya keluar daripada kesusahan ketika belayar, mereka akan mengorbankan seorang gadis sunti dengan memenggal kepalanya di haluan jong. ${ }^{41}$

Di dalam buku berjudul Commentaries of the Great Alfonso Dalborquerque pula, kita boleh melihat petikan di bawah ini:

At the time when Alfonso Dalboquerque set sail for India after having captured Malacca, there had arrived two of their Gores ships at the gate of Singapura, and they were coming to Malacca, but by the advice of the Lassamane, who was the king of Malacca's admiral of the sea, they remained where they were, and would not pass up, having learned that Malacca had been taken by the Portuguese; but when the governors of the land were informed of their position, they sent a safeguard for them, and a flag of truce, and they came on immediately. ${ }^{42}$

Gores yang dimaksudkan di dalam petikan tersebut diyakini merujuk kepada pedagang Ryukyu. Ini adalah kerana pedagang Arab memanggil pedagang Ryukyu dengan sebutan yang hampir sama, iaitu al-Ghur. Kunjungan pedagang Ryukyu itu dipercayai merupakan kunjungan terakhir mereka ke Melaka. Selepas Melaka ditakluki oleh Portugis, pedagang Ryukyu beralih ke Patani pula. Hal ini dicatatkan di dalam dua catatan Portugis.

Pertama, petikan di dalam surat bertarikh tahun 1536 yang ditulis oleh seorang tahanan Portugis bernama Vasco Calvo di Canton, China, berbunyi, "In addition, in the sea off the coast of Fukien there are Lequeos. Every year they trade goods at Patani and Soyam (Siam). In the periods of the Malaccan kings they used to go to Malacca...".

Kedua, petikan di dalam buku berjudul The Book of Duarte Barbosa pula berbunyi, "The Malacca people say that they "Liquii." people of the islands called "Lequeos" are better men, and richer and more eminent merchants than the Chins. Of these folks we as yet know but little, as they have not yet come to Malacca since it has been under the King our Lord." 43

\section{Kesimpulan}

Kerajaan Ryukyu ialah sebuah kerajaan yang kecil di Asia Timur. Wilayahnya disempadani oleh China di timur dan Korea serta Jepun di utara. Walaupun Kerajaan Ryukyu dikelilingi oleh kerajaan-kerajaan yang lebih besar di sekitarnya, Kerajaan Ryukyu memainkan peranan yang amat penting dalam perdagangan maritim di antara China, Jepun, Korea dan Asia Tenggara antara kurun ke-14 hingga kurun ke-16 Masihi. Kerajaan Ryukyu menyedari bahawa sebagai sebuah negara kepulauan yang tidak mempunyai hasil bumi yang banyak, negaranya tidak boleh menutup pintu dan hidup bersendirian. Hubungan diplomatik dan perdagangan dengan negara-negara jiran seperti China, Korea dan Jepun serta pelabuhanpelabuhan di Asia Tenggara perlu dijalankan demi kelangsungan hidup rakyat dan negaranya.

Status sebagai kerajaan uftian kepada China dan polisi Ming Haijin oleh Dinasti Ming terhadap orang Cina dimanfaatkan oleh Kerajaan Ryukyu dengan menguasai 
perdagangan di Asia Timur dan menjadi jambatan penghubung di antara Asia Timur dengan Asia Tenggara. Sekurang-kurangnya 109 buah kapal telah belayar dari Ryukyu ke Asia Tenggara bagi tujuan menjalin hubungan diplomatik dan perdagangan. Pedagangpedagang Ryukyu mengambil barang-barang dari China, Korea dan Jepun lalu membawanya ke pelabuhan-pelabuhan di Asia Tenggara untuk didagangkan. Kemudian, barang-barang yang diperoleh di pelabuhan-pelabuhan Asia Tenggara dibawa pula ke China, Korea dan Jepun untuk tujuan yang sama. Sebahagian barang-barang itu dijadikan ufti kepada Maharaja China.

Di Asia Tenggara, kerajaan Ryukyu turut menjalinkan hubungan diplomatik dan perdagangan dengan Kerajaan Melaka selain Siam, Palembang, Jawa, Sumatera, Patani, Annam dan Sunda. Kerajaan Melaka pada kurun ke-15 merupakan sebuah empayar yang menguasai hampir keseluruhan semenanjung Tanah Melayu dan timur Sumatera. Pedagang-pedagang Ryukyu amat dihormati di Melaka kerana mereka jujur dan berkelakuan baik. Sultan-sultan Melaka yang menjalin hubungan dengan Kerajaan Ryukyu dari tahun 1463 hingga tahun 1511 Masihi ialah Sultan Mansur Shah, Sultan Alauddin Riayat Shah dan Sultan Mahmud Shah. Manakala di sebelah kerajaan Ryukyu pula ialah Raja Sho Toku, Raja Sho En, Raja Sho Sen-I dan Raja Sho Shin. Apabila Melaka jatuh ke tangan Portugis pada tahun 1511 Masihi, pedagang-pedagang Ryukyu tidak lagi mengunjungi Melaka. Mereka beralih ke Patani yang ketika itu berkembang pesat menjadi pusat perdagangan menggantikan Melaka di Semenanjung Tanah Melayu.

Bibit-bibit keruntuhan Kerajaan Ryukyu bermula dengan penjajahan Satsuma-Han dari Kagoshima dengan restu Keshogunan Tokugawa di Edo. Walaupun berada di bawah kekuasaan Satsuma-Han, Kerajaan Ryukyu masih lagi menghantar ufti kepada China dan menjalankan aktiviti perdagangan walaupun tidak serancak dahulu. Akhirnya, Kerajaan Ryukyu lenyap dari peta dunia apabila Ryukyu secara rasmi diserap ke dalam Jepun pada tahun 1879 ketika zaman Pemulihan Meiji. Pada hari ini, Ryukyu dikenali sebagai Okinawa Prefecture.

\section{Nota}

1 Ryukyu, Encyclopedia of Britannia, http://library.ebonline.com/levels/adults/article/64566, diakses pada 1 Mei 2016.

2 “Prefecture" ialah terjemahan dalam bahasa Inggeris bagi perkataan “todofuken" (都道拊県). Perkataan ini boleh disamakan dengan perkataan "negeri" atau "wilayah" dalam bahasa Melayu. Pentadbiran negara Jepun dibahagikan kepada 47 buah prefecture.

3 Ryukyu, Encyclopedia of Britannia, http://library.ebonline.com/levels/adults/article/64566, diakses pada 1 Mei 2016.

4 Anji (按司) ialah segolongan kelas bangsawan di Ryukyu yang mempunyai kuasa ke atas tanah masing-masing, tetapi pada masa yang sama memberikan kesetiaan kepada raja.

5 George H. Kerr, Okinawa The History of an Island People, Vermont: Turtle Publishing, 2000, hlm. 83.

6 Nama Raja-raja Chuzan, Nanzan dan Hokuzan ditransliterasi berdasarkan sebutan bahasa Cina di dalam Ming Hui Tian.

$7 \quad$ Hsu Yun-Tsiao, Notes on the Relations Between Ryukyu Islands and Malacca Sultanate During 14641511, Persidangan Antarabangsa Mengenai Sejarah Asia, 5-10 Ogos 1968, Jabatan Sejarah, Universiti Malaya, hlm. 2.

8 Ibid., hlm. 1.

9 Hamashita Takeshi, China, East Asia and the Global Economy, London: Routledge, 2008, hlm. 57.

10 Satsuma-Han (薩攀蕃) atau Satsuma domain ialah sebuah wilayah kebangsawanan Jepun ketika Zaman Edo dan Meiji. Ketua bagi sesebuah Han dikenali sebagai daimyou (大名). Daimyou memberikan kesetiaan kepada Maharaja Jepun.

11 Hamashita Takeshi, China, East Asia and the Global Economy, hlm. 57. 
Anthony Reid, Charting The Shape of Early Modern Southeast Asia, Chiang Mai: Silkworm Books, 1999, hlm. 89.

Sakamaki Shunzo, 'Ryukyu and Southeast Asia', The Journal of Asian Studies, Vol. 23, No. 3, Mei 1964, hlm. 383.

Ibid.

Ibid.

Hamashita Takeshi, China, East Asia and the Global Economy, hlm. 57.

Kobata Atsushi dan Matsuda Mitsugu, Ryukyuan Relations with Korea and the South Sea Countries: An Annotated Translation of Documents in the Rekidai Hoan, Kyoto: Kawakita Printing, 1969, hlm. vi. Sakamaki Shunzo, 'Ryukyu and Southeast Asia', hlm. 384.

Kenneth. R. Robinson, 'Shaping Maritime East Asia through Choson Korea' dalam Fujita Kayoko, Momoki Shiro dan Anthony Reid (ed.), Offshore Asia Maritime Interactions in Eastern Asia Before Steamships, Singapore: Institute of Southeast Asian Studies, 2013, hlm. 190.

Sakamaki Shunzo, 'Ryukyu and Southeast Asia', hlm. 383.

Terdampar atau karam.

Richard Pearson, Ancient Ryukyu: An Archaeological Study of Island Communities, Honolulu: University of Hawai'i Press, 2013, hlm. 198.

Ibid., hlm. 207.

Ibid., hlm. 198.

Sakamaki Shunzo, 'Ryukyu and Southeast Asia', hlm. 387.

Ibid., hlm. 388.

T'ien-shun 7/8/4 bermaksud 4 haribulan 8 tahun ke-7 T'ien-shun dalam kalendar lunar Cina semasa pemerintahan Dinasti Ming di negara China.

Kobata Atsushi dan Matsuda Mitsugu, Ryukyuan Relations with Korea, hlm. 106.

Ibid., hlm. 114.

Ibid., hlm. 116-117.

Hashim Musa dan Rohaidah Kamaruddin, Hang Tuah Catatan Okinawa, Serdang: Penerbit Universiti Putra Malaysia (UPM), 2015, hlm. 88-90. Ahmat Adam sebaliknya menyangkal pendapat yang telah diterima umum selama ini bahawa Laksamana Melaka yang tersohor itu bernama Hang Tuah kerana terdapat pantang larang dalam kepercayaan Melayu dalam penyebutan nama sebenar seseorang pembesar Melayu. Seorang pembesar Melayu hanya dikenali dengan nama gelarannya, bukan dengan nama sebenar pembesar itu. Beliau juga menyatakan Sulalatus Salatin merupakan sebuah karya kesusasteraan yang tidak boleh dianggap sebagai sumber sejarah kerana terdapat banyak mitos di dalamnya dan watak Hang Tuah juga sekadar watak sastera, bukan tokoh sejarah. Malah karya itu juga banyak dipengaruhi oleh bahasa dan kesusasteraan Jawa dan telah disalin banyak kali oleh ramai pengarang sehingga terdapat tokok tambah dan kesilapan ejaan. Lihat Ahmat Adam, Antara Sejarah dan Mitos: Sejarah Melayu dan Hang Tuah dalam Historiografi Malaysia, Petaling Jaya: SIRD, 2016, hlm. 125-132.

Hao San-lien ta-pu, hsi-chiao-ta-qu, chiao-ta-pu dan nan-mo-na-pu ialah jenis kain atau tekstil.

Pieh-pu hao-pe, pieh-ti-pu, nan-mu-na, shan-nan-pa hao-pe dan tso-ta ialah jenis kain atau tekstil.

Je-na-li, pi-pu, hsi shao-ta-pu dan shao-ta-pu ialah jenis kain atau tekstil.

Shan-nan-pu, nan-mu-na, huo-wai, sheng-chia-sha dan shan-nan-pu wen-ti-li ialah jenis kain.

Chi-ti-pu, hsing-chi-chih, lin-wu-na dan shan-nan-pi ialah jenis kain atau tekstil.

Wako (sebutan Jepun) atau wokou (sebutan Cina) atau waegu (sebutan Korea) ialah lanun yang bergerak aktif di perairan Asia Timur ketika era Kamakura dan awal era Edo. Walaupun istilah ini kerap merujuk kepada lanun dari Jepun, tetapi ada juga dalam kalangan mereka yang berasal dari China.

Kemungkinan arak Melaka yang dimaksudkan itu ialah tuak.

Armando Cortesao (ed.), The Suma Oriental of Tome Pires, New Delhi: Asian Education Services, 2005, hlm. 130-131.

Ibid., hlm. 129-131.

Ibid., hlm. 130.

Kobata Atsushi dan Matsuda Mitsugu, Ryukyuan Relations with Korea, hlm. 126.

Ibid., hlm. 125. 